\title{
Pars Plana Vitrectomy in Advanced Coats' Disease
}

\author{
Gulipek Muftuoglua Gokhan Gulkilik \\ aDepartment of Ophthalmology, Cerrahpasa Medical Faculty, and 'bisli Etfal \\ Education and Research Hospital, Eye Clinic, Istanbul, Turkey
}

\section{Key Words}

Advanced Coats' disease $\cdot$ Pars plana vitrectomy $\cdot$ Retinal detachment $\cdot$ Subretinal fluid drainage $\cdot$ Silicone oil tamponade $\cdot$ Phacoemulsification surgery

\begin{abstract}
Purpose: To report 5 cases of advanced Coats' disease managed with pars plana vitrectomy and silicone oil tamponade.

Methods: Five patients with advanced Coats' disease and serous or tractional retinal detachment underwent pars plana vitrectomy with internal drainage, endolaser photocoagulation and silicone oil tamponade. One patient had combined phacoemulsification-vitrectomy surgery. Of the 5 patients, 1 had intravitreal hemorrhage and a retinal macrocyst and 1 had a retinal cyst. Follow-up period was 1-6 years.

Results: All patients had improved visual acuity after surgery. No intraoperative or postoperative complications were observed in any of the patients. The retina was attached and the disease was stable in all patients during follow-up. Two patients had cataract formation, and in one of them the cataract was successfully managed with phacoemulsification surgery.

Conclusion: Pars plana vitrectomy, subretinal fluid drainage, and long-term silicone oil tamponade are effective methods in the management of advanced Coats' disease. Early and prompt management can prevent visual loss and secondary complications.
\end{abstract}

\section{Introduction}

Coats' disease is an idiopathic condition characterized by abnormal telangiectatic retinal vessels and intra- and subretinal exudation. It was first described by George Coats in 1908 [1]. The disease usually occurs unilaterally in young males, and the mean age at diagnosis is 8-16 years [2]. The clinical findings show great variability ranging from mild vascular abnormalities to extensive areas of retinal telangiectasia associated with massive leakage and exudative retinal detachment. If left untreated the disease shows progressive worsening which can lead to neovascular glaucoma and phthisis bulbi, sometimes requiring enucleation $[3,4]$. Scleral buckling with subretinal fluid drainage and cryotherapy or laser photocoagulation have been shown to be effective in the treatment of 
retinal detachment in Coats' disease [5]. Pars plana vitrectomy with silicone oil tamponade has been reported to be an alternative treatment in Coats' disease with retinal detachment $[6,7]$. In this study, we report the long-term surgical outcomes of pars plana vitrectomy and silicone oil injection in 5 cases with advanced Coats' disease with retinal detachment. Table 1 demostrates patient characteristics, preoperative and postoperative findings.

\section{Case Reports}

\section{Case 1}

A 6-year-old girl presented with poor visual acuity and deviation in her left eye. Visual acuities were $20 / 20$ and counting fingers at $0.5 \mathrm{~m}$ in the right and left eye, respectively. There was no pathology in the right eye. Fundus examination of the left eye revealed massive lipid exudation in the posterior pole and around the arcades with exudative retinal detachment extending from the inferior border of the optic disc to the temporal periphery (fig. 1a). Fluorescein angiography was performed to demonstrate the extent of abnormal telangiectatic retinal vessels.

Following the diagnosis of Coats' disease with retinal detachment, she underwent surgery for pars plana vitrectomy. After core vitrectomy and posterior hyaloid removal, a drainage retinotomy was performed to remove subretinal fluid and lipid accumulation. The retina was flattened with fluid-air exchange followed by endolaser photocoagulation around the retinotomy, areas with abnormal vasculature, and the whole midperiphery. Surgery was completed with air-silicone exchange.

No postoperative complications were observed during follow-up. Her visual acuity improved to 20/200 and 20/100 at week 1 and month 1 after surgery, respectively. Thirty-six months after surgery, the retina was attached and no silicone oil emulsification was present (fig. 1b). Visual acuity decreased to a level of 20/200 due to the development of a nuclear cataract.

\section{Case 2}

An 18-year-old male presented with decreased visual acuity in his left eye. His visual acuities were $20 / 40$ and hand motions in the right and left eye, respectively. Anterior segment findings were normal in both eyes. Fundus examination revealed bilateral retinitis pigmentosa associated with abnormal telangiectatic retinal vessels, which was worse in the left eye compared to the right one. An inferior exudative retinal detachment with massive lipid exudation was extending from the inferior nasal border of the optic disc to the inferior temporal periphery including the macula in the left eye. There was also minimal intravitreal hemorrhage in the inferior temporal periphery (fig. 2a).

The right eye was treated with laser photocoagulation in the areas with abnormal vasculature. Pars plana vitrectomy with internal drainage and silicone oil tamponade was performed in the left eye. Endolaser photocoagulation was performed around the drainage retinotomy and in the areas with abnormal vasculature revealed by fundus fluorescein angiography. Silicone oil was left in the eye for 18 months. No intraoperative or postoperative complications were observed. The disease was stable and his visual acuity improved to 20/400 and stayed at this level throughout the follow-up period of 24 months. (fig. 2b).

\section{Case 3}

A 25-year-old male with Coats' disease was referred to our clinic with intravitreal hemorrhage in the right eye. His visual acuities were light perception and 20/20 in the right and left eye, respectively. There was no pathology in the left eye. Vitreous hemorrhage in the right eye prevented fundus examination. Ultrasonographic examination of the right eye revealed intravitreal hemorrhage and a retinal macrocyst. (fig. 3a). 
The patient underwent pars plana vitrectomy. After core vitrectomy and removal of the hemorrhage, the retinal macrocyst was exposed (fig. 3b). The content of the cyst was drained through a retinotomy. After the fluid-air exchange, endolaser photocoagulation was performed around the retinotomy and in the areas with abnormal retinal vasculature. The surgery was completed with air-silicone oil exchange. The silicone oil was removed from the eye 6 months after surgery. The disease was stable and no postoperative complications were observed apart from the cataract formation. He underwent phacoemulsification surgery and his final visual acuity was 20/200 at the end of the 6-year period (fig. 3c).

Case 4

A 17-year-old female with Coats' disease was referred to our clinic due to recent decrease in visual acuity in the left eye. Her visual acuities were 20/20 and light perception in the right and left eye, respectively. There was no pathology in the right eye. Anterior segment examination in the left eye was significant for nuclear cataract. Posterior segment examination of the left eye revealed tractional retinal detachment with massive lipid exudation and microvascular abnormalities.

The patient underwent combined pars plana vitrectomy and phacoemulsification surgery. After removal of the cataract, the anterior chamber was filled with viscoelastic and pars plana vitrectomy was performed. After removal of the core, vitreous tractional bands and preretinal membranes were dissected. A drainage retinotomy was performed to remove subretinal fluid and exudates with fluid-air exchange. Endolaser photocoagulation was performed around the retinotomy and in the areas with abnormal vasculature. The surgery was completed with air-silicone oil exchange and hydrophobic acrylic IOL was implanted in the bag. The silicone oil was left in the eye for 2 years. No intra- or postoperative complication was observed. The disease was stable and visual acuity improved to 20/400 and stayed at this level throughout the follow-up period of 24 months.

\section{Case 5}

An 18-year-old male with a diagnosis of Coats' disease presented to our clinic with decreased visual acuity in the left eye. His visual acuities were $20 / 20$ and light perception in the right and left eye, respectively. There was no pathology in the right eye. The anterior segment findings were normal in the left eye. Fundus examination of the left eye revealed massive lipid exudation in the posterior pole, a totally detached retina with tractional bands, and abnormal telangiectatic vessels. A retinal cyst was evident on fundus ultrasonography.

The patient underwent pars plana vitrectomy. After removal of the tractional bands, a retinotomy was performed to drain subretinal lipid exudates. The retinal cyst was removed by retinectomy. The retina was attached with perfluorocarbon liquid, and endolaser photocoagulation was performed around the retinotomy and retinectomy and in the areas with abnormal vasculature. The surgery was completed with fluid-silicone exchange. At the end of the 12 months, visual acuity was 20/200 with no major complication.

\section{Discussion}

The most effective management of early Coats' disease with telangiectatic vessels and exudation is cryotherapy or laser photocoagulation of the retina. However, there is no gold standard in the management of Coat's disease with exudative retinal detachment. Harris reported that without treatment, one quarter of the patients with Coats' disease with exudative retinal detachment had developed neovascular glaucoma, which often required primary enucleation [8]. Other studies also reported the importance of early diagnosis and prompt management in Coats' disease with exudative retinal detachment [3-5]. 
Vitreoretinal surgery has become an alternative treatment in the management of complex retinal detachment. Yoshizumi et al. reported a successful management of advanced Coats' disease with pars plana vitrectomy and air-fluid exchange [9]. Recently, Kranias and Krebs reported a successful vitrectomy and internal air-fluid exchange without scleral buckling. They stated that scleral buckling might play a very limited role in the management of retinal detachment in Coats' disease [10]. Schmidt-Erfurth and Lucke reported that advanced Coats' disease could be managed with scleral buckling, pars plana vitrectomy, internal drainage of the subretinal fluid and tamponade with silicone oil [7]. They stated that useful vision was obtained in all three eyes, but removal of silicone oil was required in one eye due to complications.

In the present study, we reported five cases of advanced Coats' disease managed with vitrectomy, internal subretinal fluid drainage and long-term silicone oil tamponade without scleral buckling. To our knowledge, this is the largest number of patients reported in the literature. Furthermore, in patient 4 combined pars plana vitrectomy with phacoemulsification surgery was performed. To our knowledge, this is the first case of combined surgery in Coats' disease reported in the literature. The result of this surgery was not different than in the other cases. The visual acuities were improved after surgery and maintained throughout the follow-up period in all eyes. There were no secondary complications related to long-term silicone oil tamponade. The disease process stabilized in all patients, and none of them required repeat pars plana vitrectomy. Two patients had cataract formation, and in one of them the cataract was successfully managed with phacoemulsification surgery. We believe that early and prompt management with pars plana vitrectomy, subretinal fluid drainage, and long-term silicone oil tamponade can prevent visual loss and secondary complications of advanced Coats' disease.

\section{Disclosure Statement}

The authors have no financial/conflicting interests to disclose. 


\begin{tabular}{c|l|l|l}
$\begin{array}{c}\text { Case Reports in } \\
\text { Ophthaimology }\end{array}$ & $\begin{array}{l}\text { Case Rep Ophthalmol 2011;2:15-22 } \\
\text { DOI: 10.1159/000323616 }\end{array}$ & $\begin{array}{l}\text { Published online: } \\
\text { January 7, 2011 }\end{array}$ & $\begin{array}{l}\text { O 2011 S. Karger AG, Basel } \\
\text { ISSN 1663-2699 } \\
\text { www.karger.com/cop }\end{array}$ \\
\hline
\end{tabular}

Table 1. Patient characteristics, preoperative and postoperative findings

\begin{tabular}{llllll}
\hline & Patient 1 & Patient 2 & Patient 3 & Patient 4 & Patient 5 \\
\hline Age & 6 & 18 & 25 & 17 & 18 \\
Gender & Female & Male & Male & Female & Male \\
Eye & Right & Left & Right & Left & Left \\
Retinal telangiectasia & + & + & + & + & + \\
Pigmentary retinopathy & - & + & - & - & - \\
Vitreous hemorrhage & - & + & + & - & - \\
Retinal macrocyst & - & - & - & - & + \\
Retinal detachment & + & + & LP & LP & + \\
Preoperative VA & $20 / 800$ & HM & - & + & - \\
Cataract surgery & - & 18 months & 6 months & 24 months & 12 months \\
Duration of silicone oil & 36 months & - & cataract & - & - \\
Postoperative complication & cataract & $20 / 400$ & $20 / 200$ & $20 / 400$ & $20 / 200$ \\
Final VA & $20 / 200$ & 200 & & & \\
\hline
\end{tabular}

$\mathrm{VA}=$ Visual acuity; $\mathrm{HM}=$ hand motions; $\mathrm{LP}=$ light perception.

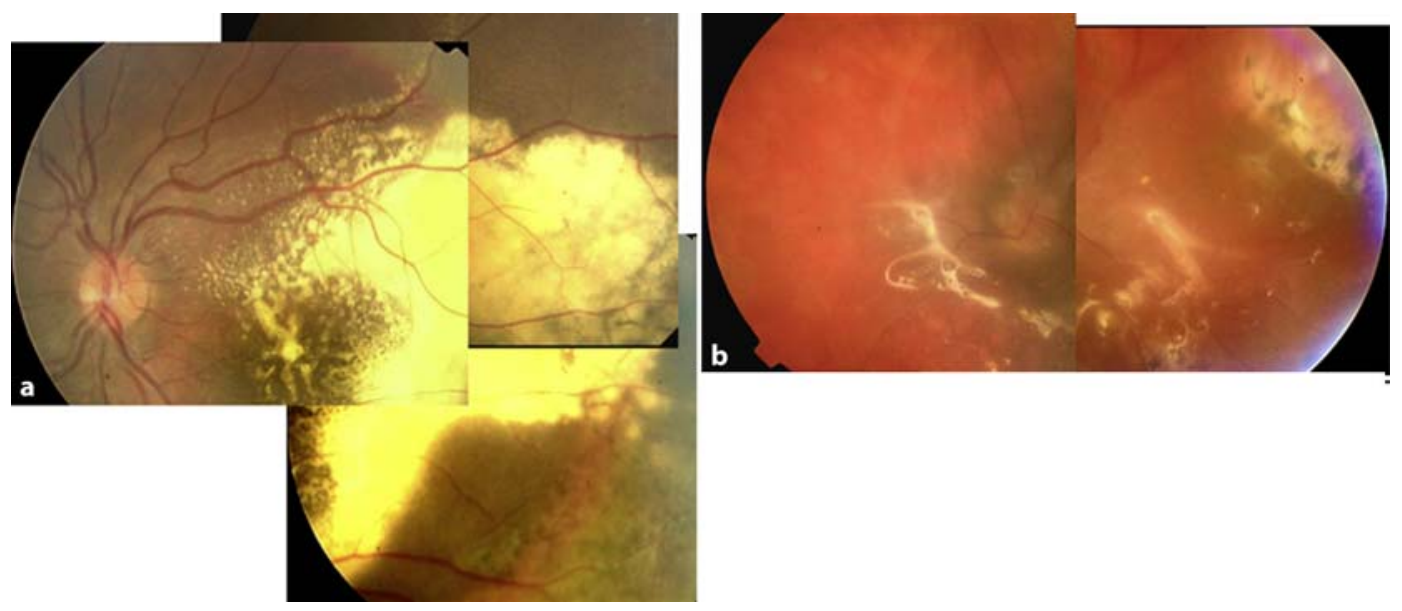

Fig. 1. a Massive lipid exudation in the posterior pole and around the arcades with exudative retinal detachment extending from the inferior border of the optic disc to the temporal periphery. $\mathbf{b}$ Fundus photograph showing the attached retina with no lipid exudation 36 months after surgery. 


\begin{tabular}{c|l|l|l}
$\begin{array}{c}\text { Case Reports in } \\
\text { Ophthainology }\end{array}$ & $\begin{array}{l}\text { Case Rep Ophthalmol 2011;2:15-22 } \\
\text { DOI: 10.1159/000323616 }\end{array}$ & $\begin{array}{l}\text { Published online: } \\
\text { January 7, 2011 }\end{array}$ & $\begin{array}{l}\text { O 2011 S. Karger AG, Basel } \\
\text { ISSN 1663-2699 } \\
\text { www.karger.com/cop }\end{array}$ \\
\hline
\end{tabular}

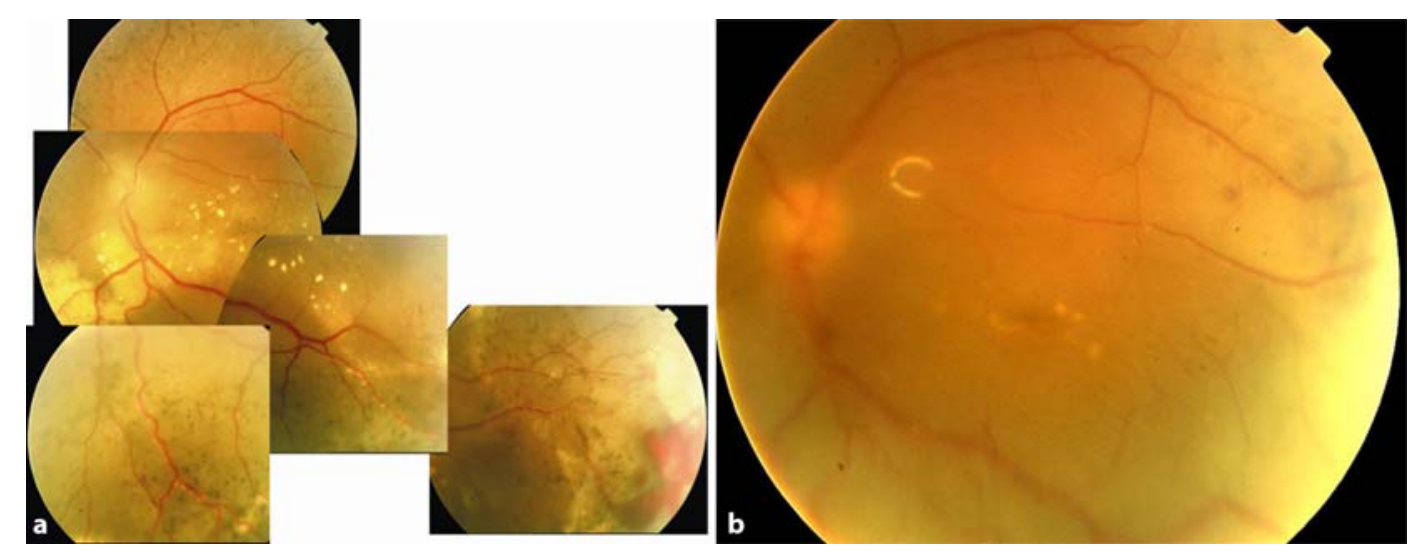

Fig. 2. a Fundus photograph showing pigmentary changes with abnormal vasculature and lipid exudation involving the macula. Note the hemorrhage in the inferotemporal quadrant. Visual acuity was hand motions. b Postoperative fundus photograph of the same patient. The retina was attached and there was no lipid exudation. The visual acuity was $20 / 400$. 


\begin{tabular}{l|l|l|l} 
Case Reports in & $\begin{array}{l}\text { Case Rep Ophthalmol 2011;2:15-22 } \\
\text { DOI: } 10.1159 / 000323616\end{array}$ & $\begin{array}{l}\text { Published online: } \\
\text { January 7, 2011 }\end{array}$ & $\begin{array}{l}\text { ○ 2011 S. Karger AG, Basel } \\
\text { ISSN 1663-2699 } \\
\text { www.karger.com/cop }\end{array}$ \\
\hline
\end{tabular}
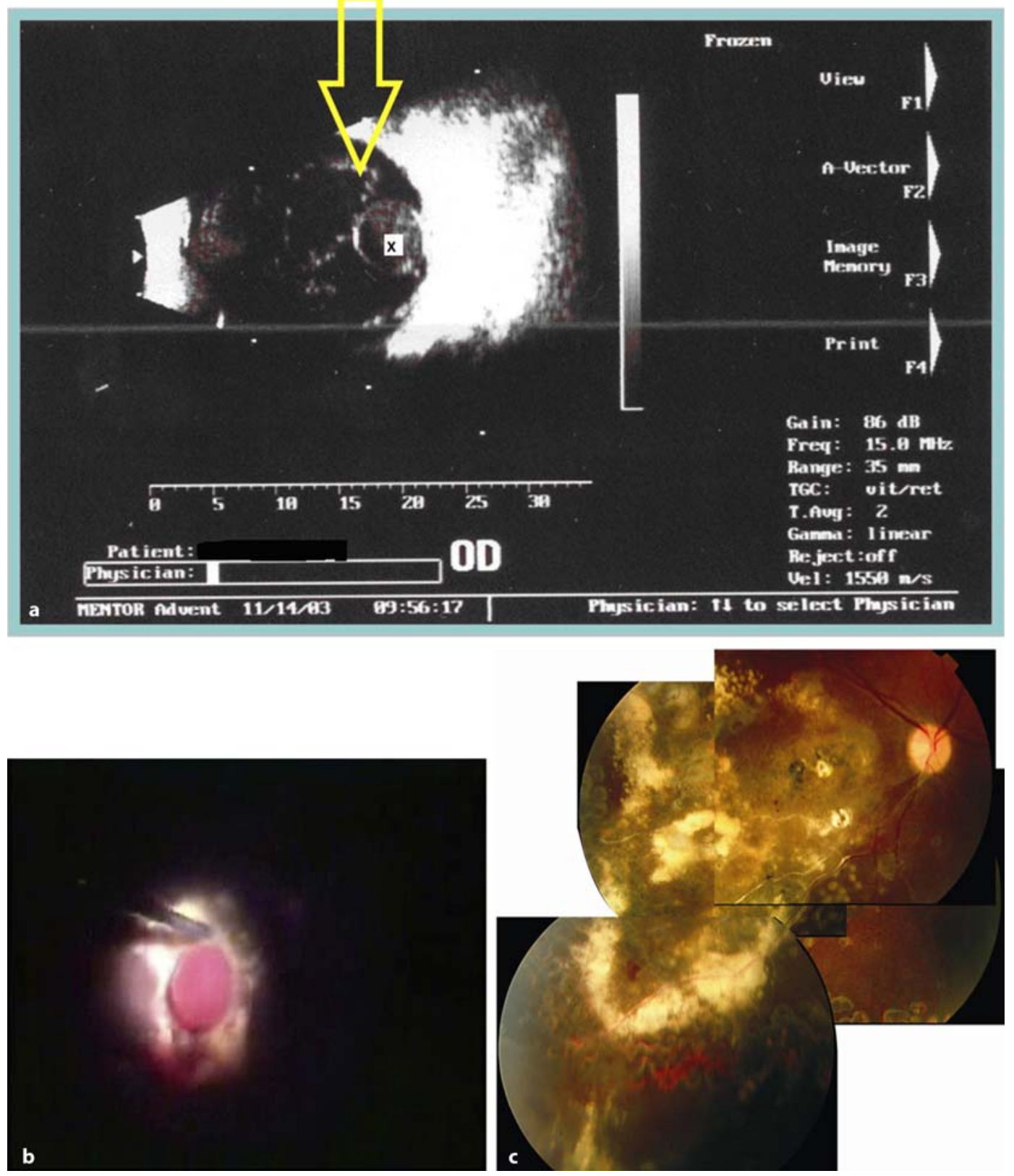

Fig. 3. a Ultrasonographic view of the right eye showing vitreous hemorrhage with a retinal macrocyst. The arrow points to the posterior hyaloids and the $\mathrm{x}$ shows the retinal macrocyst. $\mathbf{b}$ Intraoperative photograph of the same patient. After removal of the vitreous hemorrhage, the retinal macrocyst was exposed. c Fundus photograph showing lipid exudation inferotemporal to the fovea. The macrocyst was free of pigmentary changes and subretinal fibrosis.

\section{References}

1 Coats G: Forms of retinal dysplasia with massive exudation. R Lond Ophthalmol Hosp Rep 1908;17:440.

2 Haller JA: Coats' disease and retinal telengiectasia; in Yanoff M, Duker JS (eds): Ophthalmology 2nd ed. St. Louis, MO: Mosby Inc. 2004, pp 896-901. 
-3 Shields JA, Shields CL, Honavar S, Demirci H: Clinical variations and complications of Coats disease in 150 cases: The 2000 Sanford Gifford Memorial Lecture. Am J Ophthalmol 2001;131:561-571.

4 Char DH: Coats's syndrome: long-term follow-up. Br J Ophthalmol 2000;84:37-39.

-5 Shields JA, Shields CL, Honavar SG, Demirci H, Cater J: Classification and management of Coats disease: the 2000 Proctor Lecture. Am J Ophthalmol 2001;131:572-583.

6 Inoue M, Hirakata A, Miki D, Hida T, Kohda F, Ogino K: Vitrectomy in Coats' disease. Nippon Ganka Gakkai Zasshi 1996;100:358-362.

7 Schmidt-Erfurth U, Lucke K: Vitreoretinal surgery in advanced Coats' disease. Ger J Ophthalmol 1995;4:32-36.

8 Harris GS: Coats' disease, diagnosis and treatment. Canad J Ophthalmol 1970;4:311-320.

-9 Yoshizumi MO, Kreiger AE, Lewis H: Vitrectomy techniques in late-stage Coats'-like exudative retinal detachment. Documenta Ophthalmologica 1995;90:387-394.

10 Kranias G, Krebs TP: Advanced Coats' disease successfully managed with vitreo-retinal surgery. Eye 2002;16:500-501. 